\title{
openheart Biological effect of microengineered grooved stents on strut healing: a randomised OCT-based comparative study in humans
}

\author{
Boris Vesga, ${ }^{1,2}$ Hector Hernandez, ${ }^{1,2}$ Sergio Higuera, ${ }^{1,2}$ Pawel Gasior, \\ Dario Echeveri, ${ }^{5}$ Juan A Delgado, ${ }^{6}$ Antonio Dager, ${ }^{7}$ Camilo Arana, ${ }^{7}$ \\ Charles Simonton, ${ }^{8}$ Akiko Maehara, ${ }^{9}$ Julio Palmaz, ${ }^{10}$ Juan F Granada ${ }^{11}$
}

To cite: Vesga B, Hernandez $\mathrm{H}$, Higuera S, et al. Biological effect of microengineered grooved stents on strut healing: a randomised OCT-based comparative study in humans. Open Heart 2017;4:e000521. doi:10.1136/ openhrt-2016-000521

Received 22 August 2016 Revised 20 December 2016 Accepted 29 March 2017

\section{CrossMark}

For numbered affiliations see end of article.

Correspondence to Dr. Juan F Granada; jgranada@ crf.org

\section{ABSTRACT}

Objective To evaluate the biological effect of microengineered stent grooves (MSG) on early strut healing in humans by performing optical coherence tomography (OCT) analysis 3 weeks following the implantation.

Background In the experimental setting, MSG accelerate endothelial cell migration and reduce neointimal proliferation compared with bare metal stent (BMS)

Methods A total of 37 patients undergoing percutaneous coronary intervention with de novo coronary lesions were randomly assigned to either MSG $(n=19)$ or an identical BMS controls $(n=18)$. All patients underwent OCT imaging at 3 weeks. A total of 7959 struts were included in the final analysis.

Results At 3 weeks following stent implantation, almost all struts analysed ( 97\%) had evidence of tissue coverage. The percentage of partially covered struts was comparable between both groups. However, the percentage of fully embedded struts was higher in the BMS group (81.22\%, 49.75-95.52) compared with the MSG group (74.21\%, 58.85-86.38). The stent-level analysis demonstrated reduction in neointimal formation (neointimal hyperplasia area and volume reduction of $\sim 14 \%$ and $\sim 19 \%$, respectively) in the MSG versus the BMS group. In the strut-level analysis, an even greater reduction ( 22\% in neointimal thickness) was seen in the MSG group. Layered neointimal was present in $\sim 6 \%$ of the OCT frames in the BMS group while it was not present in the MSG group.

Conclusions MSG induced a more homogeneous and predictable pattern of surface healing in the early stages following stent implantation. The biological effect of MSG on stent healing has the potential to improve the safety profile of current generation drug-eluting stents. Classifications BMS, OCT, clinical trials.

\section{INTRODUCTION}

Drug-eluting stent (DES) failure is a multifactorial clinical phenomenon that continues to occur over time. ${ }^{1}$ Several studies have described delayed healing and neoatherosclerosis as the most important biological mechanisms responsible for this condition. ${ }^{2}$

\section{KEY QUESTIONS}

What is already known about this subject? Experimental studies have shown that microengineered stent grooves (MSG) accelerate strut endothelialisation and reduce neointimal proliferation compared with stents exposing flat metal surfaces.

What does this study add?

This is a first-in-man evaluation of MSG technology in patients with ischaemic heart disease due to de novo coronary artery lesions. Early 3 weeks optical coherence tomography analysis demonstrated lower levels of neointimal formation and higher level of neointimal maturity which indicates faster healing in the MSG technology.

How might this impact on clinical practice? In the setting of metallic drug-eluting stent (DES), this technology has the potential to elicit a more homogeneous and predictable healing response and to improve the clinical safety of current generation metallic DES. In addition, due to the fact that the grooves can be applied to different surfaces, it has the potential to improve the healing profile of thicker strut devices such as bioresorbable scaffolds.

In the experimental setting, accelerated strut endothelialisation results in the more rapid development of a lower and more organised neointimal response even in the absence of antiproliferative drugs. ${ }^{3}$ Then, technologies capable of accelerating strut endothelialisation have the potential to improve the safety profile of DES.

Several strategies have been developed to accelerate strut endothelialisation. ${ }^{4} 5$ Specifically, the manufacturing of dedicated microengineered stent grooves (MSG) aligned towards the direction of the coronary flow is now technologically feasible. ${ }^{6} 7$ Experimental studies have shown that MSG accelerate strut endothelialisation and reduce 


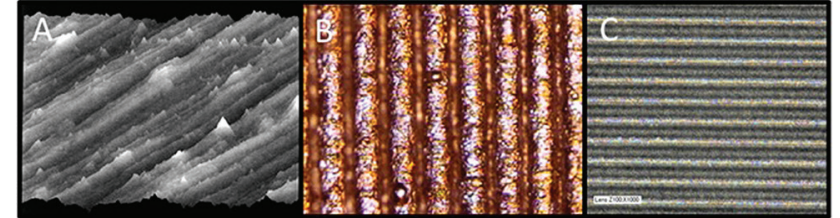

Figure 1 Early parallel microgrooves on stainless steel $316 \mathrm{~L}$ manufactured using different techniques as shown by atomic force microscope. Groove width and depth is variable because of variability in the abrasive material grain size (A). Grooves created by laser were relatively regular but the edge definition was poor because of inherent limitations of the technology and the background materials (B). Microgrooves inscribed by photolithographic technology allow much higher resolution in feature shape and dimensions $(\mathbf{C})$.

neointimal proliferation compared with stents exposing flat metal surfaces. ${ }^{38}$ In this study, we aimed to test the safety and healing profile of MSG in humans by comparing the patterns of stent healing of identical bare metal stent (BMS) exposing two different luminal surfaces (MSG vs flat) using optical coherence tomography (OCT) analysis 3 weeks following stent implantation.

\section{METHODS}

\section{Stent system description}

All devices used in this study were commercially available Multi-Link Vision stents (Abbott Vascular, Santa Clara, CA). The stents are manufactured using medical grade L-605 Cobalt Chromium (strut thickness of $\sim 80 \mu \mathrm{m}$ ). Stents were available in 18 and $23 \mathrm{~mm}$ lengths and 2.75 and $3.0 \mathrm{~mm}$ diameters. The MSG technology was applied on the luminal surface of the stents by Palmaz Scientific (Fremont, CA). Final manufacturing process was performed by Creganna Medical (Galway, Ireland). Device labels were blinded to keep the identity of both devices confidential, allowing true operator blinding through the implantation procedure.

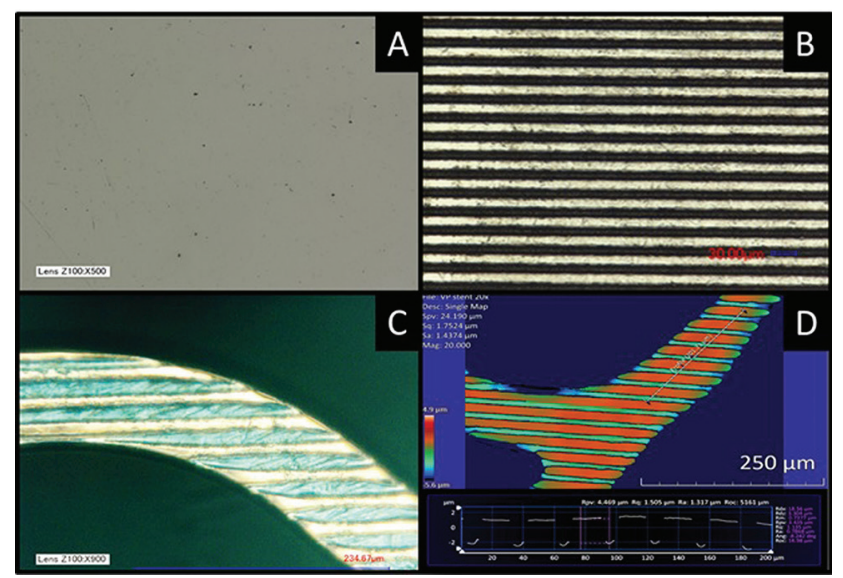

Figure 2 Representative picture of bare metal polished coupon before postprocessing (A) compared with metal coupon with inscribed grooves (B). Pictures (C) and (D) show very precise execution of grooves using novel photolithographic technology.
Microgroove stent technology

The current standard in stent technology relies on achieving a smooth flat stent surface. Over the years, different surface modification technologies have sought to influence cell colonisation of the stent inner surface by engineering defined microscopic features such as parallel microengineered grooves (figure 1). At the early stages of development of this technology, mechanical grooving was achieved by the use of calibrated abrasive materials. ${ }^{6}$ Later on, microgroove development based on laser technology allowed to establish the ideal boundary conditions for endothelial cell (EC) migration speed and groove configuration, therefore aiding optimisation of engineering parameters. ${ }^{9}$ Recent technology developments using photolithographic techniques have achieved a markedly improved resolution in the development of the microgroove patterns. ${ }^{3}$ Accuracy of the manufacturing process has improved over time and allowed the development of groove features in the micron range. The specific features of the MSG have been derived from studies assessing EC response to edge, shape and depth definition. A measurable increase in the cellular response has been seen, demonstrating a peculiar sensitivity of the EC to defined microscopic features. This cellular sensitivity is more dependent on the microgroove geometry rather than the material used (metals and polymers, data not shown). Patterns inscribed on natural alloys are less regular as those obtained in vapour-deposited alloys. The uniform size, shape and orientation of crystals as well as markedly decreased intergranular inclusions in the latter allow for higher definition patterns (figure 2).

\section{Study design}

This study was performed in compliance with the ethical principles of the Helsinki's Declaration (59th WMA General Assembly, Seoul, October 2008). The study was approved by the local hospitals and followed the governmental regulations of the government of Colombia, South America. The study design was a multicentre, prospective, randomised, two-arm study, which enrolled 40 patients randomly assigned (1:1 fashion) to either receive the MSG stent or a BMS control. All patients were scheduled for 3 weeks OCT follow-up and 6 months clinical follow-up. Eligible patients were at least 18 years of age and had a diagnosis of symptomatic ischaemic heart disease due to de novo stenotic lesions in native coronary arteries. Major adverse cardiac events (MACE) were defined as cardiac death, myocardial infarction (MI) or target vessel revascularisation (TVR) and were recorded up to 6 months following device implantation. Stent thrombosis was defined according to the Academic Research Consortium. ${ }^{10}$

\section{Clinical/angiographic inclusion and exclusion criteria}

Patients undergoing percutaneous coronary intervention (PCI) due to symptomatic coronary artery disease were included in this study. Patients were excluded if there was evidence of ST-segment elevation MI within the last 72 hours or if the patient (a) had known allergy to cobalt 
chromium, (b) allergy to aspirin or radiographic contract agents, (c) history of bleeding or coagulopathy, (d) was unable to tolerate antiplatelet therapy, (e) had an ejection fraction $<45 \%$ and (f) presence of systemic infection or underlying diseases.

Angiographic inclusion criteria included single de novo lesions ( $\geq 50 \%$ stenosis) in a native coronary artery with a reference vessel diameter $\geq 2.5 \mathrm{~mm}$ and $\leq 3.25 \mathrm{~mm}$ and $14-20 \mathrm{~mm}$ in length. Exclusion criteria included previous interventional therapy within $15 \mathrm{~mm}$ of the borders of the target lesion. In addition, the following lesions were excluded from the study: (a) left main, (b) ostial, (c) bypass graft, (d) side branch $\geq 2.0 \mathrm{~mm}$ in diameter, (e) total vessel occlusion, (f) in-stent restenosis, (g) thrombus presence or $(h)$ need for overlapping stents.

\section{Stent implantation protocol}

Eligible patients received aspirin (80-325 mg non-enteric coated) starting $>24$ hours prior to procedure and were recommended to receive loading dosages of clopidogrel. During procedure, all patients received standard anticoagulation. Predilation of the target lesion was performed with a balloon $\sim 0.5 \mathrm{~mm}$ smaller than the reference vessel diameter. All stents were implanted following standard techniques. After the procedure, all patients were recommended to receive clopidogrel ( $75 \mathrm{mg}$ daily) to be continued for at least 90 days and aspirin to be continued indefinitely.

\section{OCT analysis}

All patients underwent OCT evaluation at 3 weeks using the C7-XR imaging system (St. Jude Medical, St. Paul, $\mathrm{MN}$ ) and a motorised pullback system. Neointimal strut coverage is greatly accelerated in the absence of antiproliferative drugs. Human OCT studies have shown high degrees of stent coverage as early as $4-8$ weeks following stent implantation. ${ }^{11-14}$ We chose this early time point (3weeks) so that we could unveil potential differences in the healing response before complete surface coverage would occur. OCT images were digitally stored and analysed by the Cardiovascular Research Foundation core laboratory which was blinded to the assigned treatment. OCT cross sections (every $1 \mathrm{~mm}$ ) were selected for quantitative analysis. If a selected frame contained artefacts, the closest artefact-free frame was analysed. Morphometric analysis was performed using standard techniques.

Each analysed strut was classified as either completely or incompletely opposed to the vessel wall and according to whether there was complete tissue coverage or not. The degree of strut coverage adjudication was based on a comprehensive OCT classification. Each stent strut was classified into the following categories: definitely uncovered, uncovered with fibrin, partially covered, covered protruding and covered embedded. A definitely uncovered strut was defined as a strut not covered by tissue and both sides appear squared. An uncovered strut with fibrin was defined as a strut covered by irregular tissue and both sides appear squared. A partially covered strut was defined as a strut covered by tissue partially and at least one side having a smooth shoulder. A covered protruding strut was defined as a strut covered by tissue but extending into the lumen. An embedded strut was defined as a strut covered by tissue and not interrupting the smooth lumen contour. If the strut was covered with tissue, the tissue thickness was measured from the endoluminal surface of the tissue to the centre of the blooming artefact of the strut. To assess malapposition, we measured the distance from the centre of the stent blooming artefact to the nearby endoluminal surface of the intima. Malapposition was present if the measured distance was greater than the thickness of the stent strut $(80 \mu \mathrm{m})$. Neointimal tissue was evaluated qualitatively in cross section using an OCT classification, which is based on tissue structure and backscatter. ${ }^{15}$

\section{Statistical analysis}

Continuous data were presented as mean $\pm \mathrm{SD}$, if the distributions were skewed, the median with an IQR was provided. For continuous variables with normal distribution, the p-value was derived from Student's t-test. For continuous variables with non-normal distribution, the p-value comparing treatment groups was derived from the Wilcoxon rank-sum test. For binary variables, p-values from Fisher's exact test were used when the minimum

\begin{tabular}{|c|c|c|c|}
\hline & BMS $(n=18)$ & MSG $(n=19)$ & p Value \\
\hline Age & $69.43 \pm 9.95$ & $67.93 \pm 9.16$ & 0.62 \\
\hline Male gender & $13(72.2 \%)$ & $9(47.4 \%)$ & 0.11 \\
\hline Smoking history & $5(27.8 \%)$ & $4(21.1 \%)$ & 0.46 \\
\hline Diabetes mellitus & $6(29.4 \%)$ & $5(26.3 \%)$ & 0.55 \\
\hline Prior PCl & $3(16.7 \%)$ & $2(10.5 \%)$ & 0.47 \\
\hline $\begin{array}{l}\text { Target vessel } \\
\text { diameter }\end{array}$ & $2.96 \pm 0.16$ & $2.9 \pm 0.10$ & 0.17 \\
\hline $\begin{array}{l}\% \text { diameter } \\
\text { stenosis }\end{array}$ & $80.42 \pm 8.41$ & $82.24 \pm 10.18$ & 0.54 \\
\hline Lesion length & $15.92 \pm 2.62$ & $15.83 \pm 1.73$ & 0.90 \\
\hline Balloon diameter & $2.36 \pm 0.29$ & $2.26 \pm 0.24$ & 0.25 \\
\hline Balloon length & $15.2 \pm 2.62$ & $16.43 \pm 2.68$ & 0.16 \\
\hline $\begin{array}{l}\text { Balloon inflation } \\
\text { pressure }\end{array}$ & $9.67 \pm 3.9$ & $8.95 \pm 3.44$ & 0.54 \\
\hline $\begin{array}{l}\text { Use of } 2.75 \mathrm{~mm} \\
\text { stents }\end{array}$ & 7 (36.8\%) & 7 (33.3\%) & 0.82 \\
\hline $\begin{array}{l}\text { Use of } 23 \mathrm{~mm} \\
\text { stents }\end{array}$ & $5(26.3 \%)$ & $6(28.6 \%)$ & 0.87 \\
\hline $\begin{array}{l}\text { Moderate-severe } \\
\text { tortuosity }\end{array}$ & 17 (94.4\%) & $19(100 \%)$ & 0.47 \\
\hline $\begin{array}{l}\text { Moderate- severe } \\
\text { calcification }\end{array}$ & $3(10.5 \%)$ & $2(9.5 \%)$ & 0.36 \\
\hline TIMI 1-2 flow & $11(61.1 \%)$ & $14(73.7 \%)$ & 0.32 \\
\hline
\end{tabular}

Mean \pm SD.

BMS, bare metal stent; MSG, microengineered stent grooves;TIMI, thrombolysis in myocardial infarction score. 


\begin{tabular}{|c|c|c|c|c|}
\hline & & BMS $(n=18)$ & MSG (n=19) & $p$ Value \\
\hline \multirow[t]{12}{*}{ Quantitative findings } & Minimum lumen area $\left(\mathrm{mm}^{2}\right)$ & $4.4(3.3-6.6)$ & $4.6(3.7-5.7)$ & 0.68 \\
\hline & $\mathrm{NIH}$ at minimum lumen area site (\%) & $21.5(9.7-30.4)$ & $20.3(11.2-26.2)$ & 0.72 \\
\hline & Minimum stent area $\left(\mathrm{mm}^{2}\right)$ & $5.85(4.3-6.9)$ & $5.5(4.4-6.3)$ & 0.47 \\
\hline & Proximal reference lumen area $\left(\mathrm{mm}^{2}\right)$ & $6.5(5.9-8.8)$ & $6.9(5.0-8.3)$ & 0.72 \\
\hline & Distal reference lumen area $\left(\mathrm{mm}^{2}\right)$ & $6.2(3.4-7.5)$ & $5.3(4.3-7.5)$ & 0.69 \\
\hline & Stent length by OCT $(\mathrm{mm})$ & $18.4(18.2-19.6)$ & $18.2(17.8-22.6)$ & 0.52 \\
\hline & Lumen area $\left(\mathrm{mm}^{3} / \mathrm{mm}\right)$ & $6.2(3.9-7.8)$ & $5.7(5.0-6.9)$ & 0.71 \\
\hline & Stent area $\left(\mathrm{mm}^{3} / \mathrm{mm}\right)$ & $6.8(5.4-8.0)$ & $6.3(5.8-7.1)$ & 0.54 \\
\hline & Neointimal thickness (stent level) (mm) & $0.095(0.06-0.17)$ & $0.085(0.07-0.12)$ & 0.81 \\
\hline & Neointimal thickness (strut level) (mm) & $0.09(0.04-0.17)$ & $0.07(0.04-0.15)$ & 0.83 \\
\hline & $\mathrm{NIH}$ area $\left(\mathrm{mm}^{3} / \mathrm{mm}\right)$ & $0.7(0.3-1.3)$ & $0.6(0.4-0.9)$ & 0.83 \\
\hline & $\% \mathrm{NIH}$ volume (=NIH/stent volume) (\%) & $11.0(3.9-21.5)$ & $8.9(5,7-13.6)$ & 0.86 \\
\hline \multirow[t]{8}{*}{ Strut level findings } & Total struts analysed & $198(184-226)$ & $209(195-257)$ & 0.17 \\
\hline & A. Definitely uncovered (\%) & $0(0-0)$ & $0(0-0)$ & 0.97 \\
\hline & B. Covered with fibrin (\%) & $0(0-0)$ & $0(0-0)$ & 0.71 \\
\hline & C. Partially covered (\%) & $1.7(0.4-4.6)$ & $2.83(0.3-7.5)$ & 0.74 \\
\hline & D. Covered-protruding (\%) & $17.4(3.5-41.7)$ & $18.68(12.3-34.9)$ & 0.95 \\
\hline & E. Covered-embedded (\%) & $81.2(49.8-95.5)$ & $74.21(58.9-86.4)$ & 0.90 \\
\hline & Fully uncovered $(A+B)(\%)$ & $0.0(0.0-0.5)$ & $0.0(0-0.5)$ & 0.94 \\
\hline & Malapposed (\%) & $0(0-1.02)$ & $0(0-2.6)$ & 0.80 \\
\hline \multirow[t]{8}{*}{ Qualitative findings } & Homogeneous NIH (\%) & $76.5 \%$ & $72.2 \%$ & 1.00 \\
\hline & Heterogeneous NIH (\%) & $17.6 \%$ & $27.8 \%$ & 0.69 \\
\hline & Layered NIH (\%) & $5.9 \%$ & $0.0 \%$ & 0.49 \\
\hline & NIH with macrophage (\%) & $0(0.0 \%)$ & $1(5.3 \%)$ & 1.00 \\
\hline & NIH with peri-strut microvessel (\%) & $2(11.1 \%)$ & $1(5.3 \%)$ & 0.60 \\
\hline & NIH with any thrombus (\%) & $2(11.8 \%)$ & $2(10.5 \%)$ & 1.00 \\
\hline & Any malapposition (\%) & $7(38.9 \%)$ & $8(42.1 \%)$ & 0.84 \\
\hline & Length of malapposition (mm) & $2.4(0.4-4.2)$ & $1.9(1.4-5.5)$ & 0.91 \\
\hline
\end{tabular}

Median and IQR.

BMS, bare metal stent; MSG, microengineered stent grooves; NIH, neointimal hyperplasia.

expected cell frequency was $<5$ in any of the cells of the contingency table, otherwise the p-values were derived from Pearson's $\chi^{2}$ test. Two-sided 95\% CIs for proportions were calculated using exact methods. All statistical analyses were performed using SAS software (SAS Institute 9.4, Cary, NC).

\section{RESULTS}

\section{Demographic and procedural characteristics}

A total of 40 patients were randomized to each stent group and 37 patients (MSG $n=19$, BMS $n=18$ ) were included in the final analysis (3 patients were excluded due to poor OCT imaging quality). Both stent groups were properly matched for their baseline clinical and angiographic characteristics (table 1). Mean age and percentage of male gender were similar between the BMS and MSG groups (respectively: $69.43 \pm 9.95$ vs $67.93 \pm 9.16$, $\mathrm{p}=0.62 ; 72.2 \%$ vs $47.4 \%, \mathrm{p}=0.11)$. The percentage of diabetic patients was also comparable between both groups and it was similar to previously published DES trials $(\mathrm{BMS}=29.4 \%$ vs $\mathrm{MSG}=26.3 \%, \mathrm{p}=0.55$ ). There was no difference in terms of the angiographic characteristics of the lesions treated; mainly target vessel diameter and lesion length. A summary of the most relevant clinical and procedural characteristics is presented in table 1.

Stent-level neointimal proliferation and distribution analysis A summary of the OCT quantitative analysis is presented in table 2. The mean stent length measured by OCT was almost identical in the MSG and BMS groups. The patient (stent)-level analysis demonstrated $\sim 12 \%$ reduction in neointimal thickness (NT) and smaller variations in the MSG compared with the BMS group (means 0.07 (0.06 to 0.08 ) vs 0.08 (0.05 to 0.145$), \mathrm{p}=0.83$ ) (figure 3 ). This 

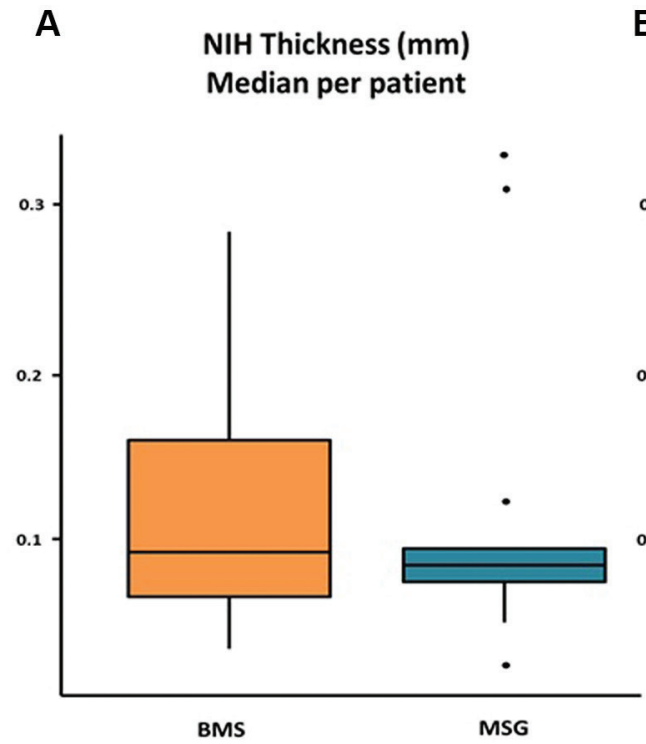

B

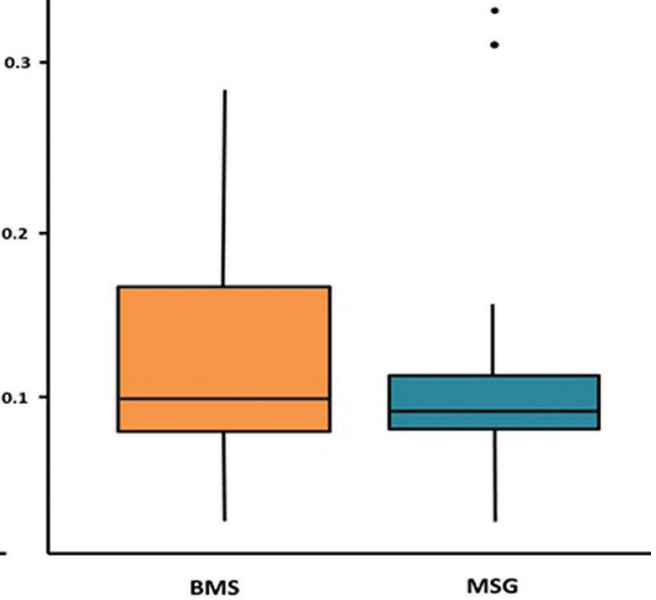

NIH Thickness (mm) among embedded struts Median per patient

BMS

Figure 3 Neointimal hyperplasia (NIH) thickness expressed as median IQR per patient in (A) whole strut population and (B) embedded struts. BMS, bare metal stent; MSG, microengineered stent grooves.

reduction in neointimal proliferation in the MSG group was consistent in other variables including neointimal hyperplasia $(\mathrm{NIH})$ area (14\% reduction) and volume ( $19 \%$ reduction). Also, $61 \%$ of all BMS control stents had a mean NT $<120 \mu \mathrm{m}$ compared with $74 \%$ of the stents in the MSG group. These results were maintained in a more detailed analysis of NT distribution when the stent was divided in tertiles (proximal, mid and distal). In this analysis, a higher percentage of struts having $<120 \mu \mathrm{m}$ was consistently seen in the MSG group regardless of stent location (respectively: distal; $61 \%$ vs $64 \%$; middle: $61 \%$ vs $71 \%$; proximal: $68 \%$ vs $74 \%$ ) (figure 4 ). Representative images of the typical OCT appearance at 3 weeks in both stent groups are shown in figure 5 .

Strut-level analysis: coverage, proliferation and maturity analysis

A total of 7959 struts were analysed ( 27 frames $\times \sim 200$ struts per stent). At 3 weeks, virtually all struts analysed had evidence of tissue coverage by OCT $(98.31 \%$ in BMS vs $97.17 \%$ in MSG). Partial strut coverage was observed in $2.8 \%$ (IQR $0.3-7.5 \%$ ) of the MSG group and $1.7 \%$ (IQR 0.4-4.6\%) of the BMS group (table 2). Covered protruding struts were observed in $18.7 \%$

\section{Population of struts with NT $<120 \mu \mathrm{m}$}

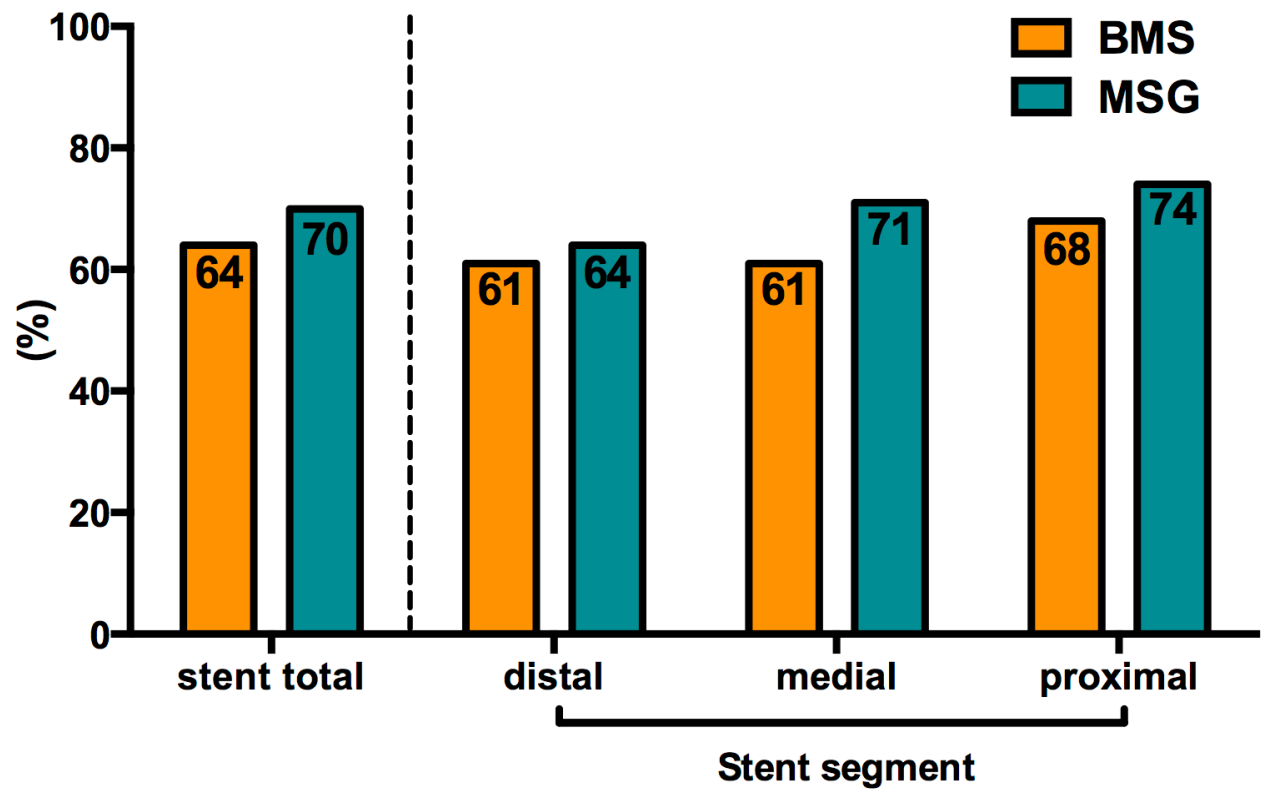

Figure 4 Distribution of struts with neointimal thickness (NT) $<120 \mu \mathrm{m}$. BMS, bare metal stent; MSG, microengineered stent grooves. 


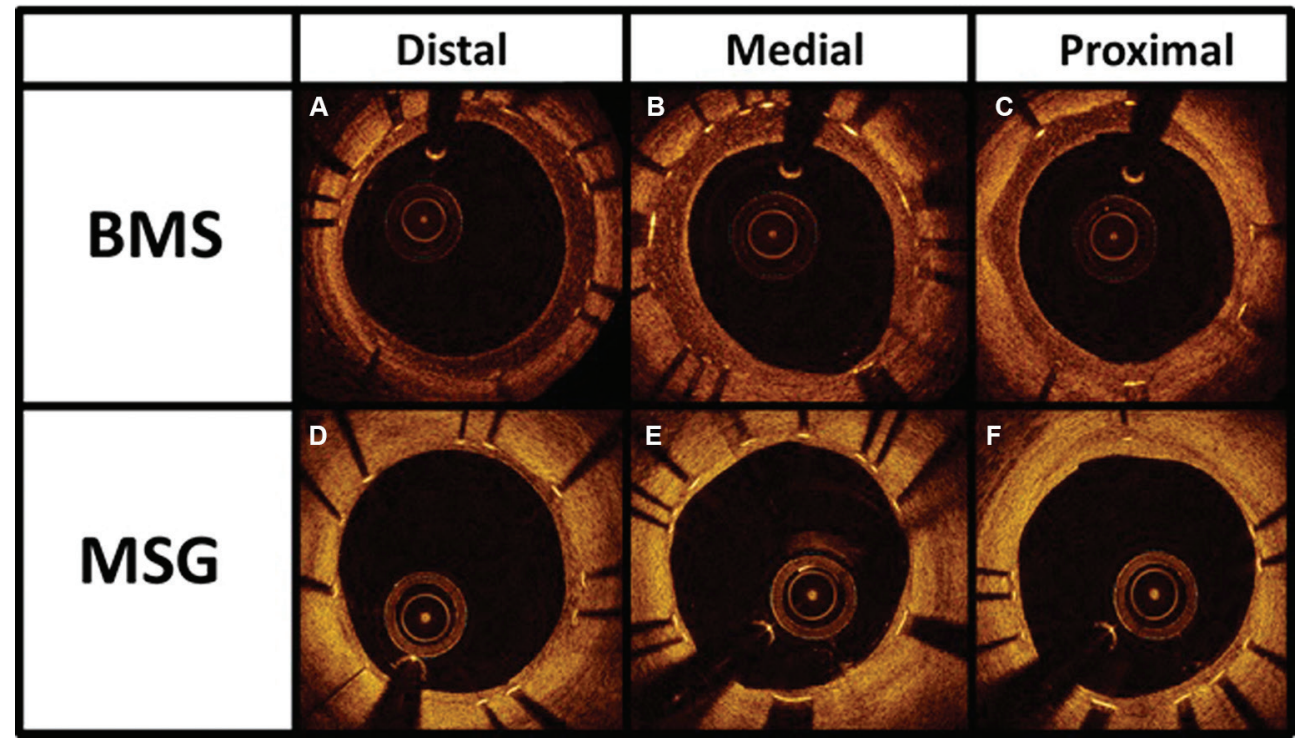

Figure 5 Optical coherence tomography analysis at 3 weeks follow-up revealed layered neointima in bare metal stent (BMS) stent $(A)$, together with heterogeneous pattern $(B, C)$ and relatively high neointimal thickness. In the microengineered stent grooves (MSG) group, neoitima appears significantly thinner, no layered neointima can be found and there is only a small fraction of heterogeneous pattern (D), most of the neointima is characterised as homogenous (E, F).

(IQR $12.25-34.9 \%)$ of the MSG group and $17.4 \%$ (IQR $3.5-41.7 \%$ ) of the BMS group. Fully covered embedded struts were observed in $74.2 \%$ in the MSG group (IQR $58.9-86.4 \%$ ) and in 81.2 (IQR $49.8-95.5 \%$ ) of the BMS group. Strut-level analysis demonstrated also reduction $(\sim 22 \%)$ in NT in the MSG compared with BMS group (median: $0.07 \mathrm{~mm}(0.04-0.15)$ vs $0.09 \mathrm{~mm}(0.04-0.17)$, $\mathrm{p}=0.83)$. In this analysis, most of the struts analysed (MSG $=70 \%$ vs $\mathrm{BMS}=64 \%$ ) had a mean $\mathrm{NT}<120 \mu \mathrm{m}$. The neointimal maturity analysis revealed that the percentage of homogenous neointima was comparable between groups $(\mathrm{MSG}=72.2 \%$ vs $\mathrm{BMS}=76.5 \%)$. However, while in the MSG group $27.8 \%$ of the struts analysed showed a heterogeneous neointima, in the BMS group there was a combination of heterogeneous $(17.6 \%)$ and layered $(5.9 \%)$ neointima (figure 6$)$.

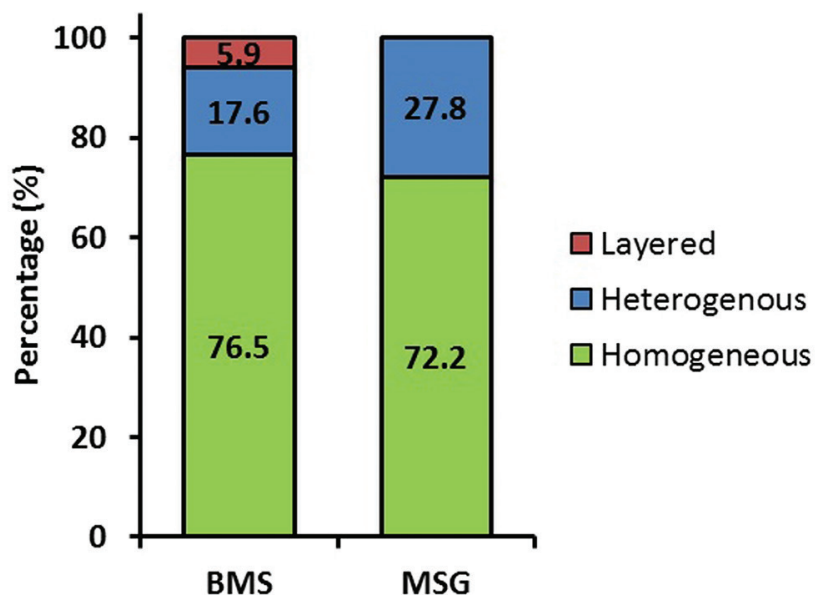

Figure 6 Neointimal maturity evaluated by optical coherence tomography. BMS, bare metal stent; MSG, microengineered stent grooves.

\section{Clinical follow-up}

During the 6 month clinical follow-up, no deaths were reported. One patient (5.3\%) in the MSG group and two patients $(11.1 \%)$ in the BMS group presented a MACE. There was a clinically driven target lesion revascularisation case in each group and additional clinically driven TVR case in the BMS group. There was a case of target-lesion-related MI reported in the MSG group (table 3). There was no case of stent thrombosis at 6 months in any of the groups.

\section{DISCUSSION}

DES continue to evolve towards the development of thinner metallic scaffolds and the use of more biocompatible polymers as drug carriers. ${ }^{16}$ Despite their undeniable clinical success, stent thrombosis and restenosis continue to occur overtime. ${ }^{17}$ Several studies suggest that both delayed healing and neoatherosclerosis

Table 3 Six-month clinical outcomes

\begin{tabular}{llll}
\hline & BMS (n=18) & MSG (n=19) & p value \\
\hline Death (total) & $0(0 \%)$ & $0(0 \%)$ & 1.00 \\
$\begin{array}{l}\text { Hierarchical MACE at } \\
6 \text { months }\end{array}$ & $2(11.1 \%)$ & $1(5.3 \%)$ & 0.52 \\
Clinically driven TLR & $1(5.6 \%)$ & $1(5.3 \%)$ & 0.74 \\
Clinically driven TVR & $1(5.6 \%)$ & $0(0 \%)$ & 0.49 \\
Target lesion-related MI & $0(0 \%)$ & $1(5.3 \%)$ & 0.32 \\
Stent thrombosis & $0(0 \%)$ & $0(0 \%)$ & 1.00
\end{tabular}

BMS, bare metal stent; MACE, major adverse cardiac event; MI, myocardial infarction; MSG, microengineered stent grooves; TLR, target lesion revascularisation; TVR, target vessel revascularisation. 
are the most important biological mechanisms responsible for late stent failures. ${ }^{18}$ Experimental data suggest that the early phases of strut healing determine the longterm healing response of DES in humans. ${ }^{19}$ Clinical in vivo imaging studies have also shown that following stent implantation, an early proliferative response leads to accelerated neointimal formation ${ }^{20}$ and restenosis. Conversely, experimental studies suggest that accelerated strut endothelialisation results in the faster development of a thinner and more organised neointimal response. ${ }^{21}$ Then, in the evolving DES, the induction of rapid endothelialisation could potentially decrease not only the dependency of antiproliferative agents but also improve the safety profile of current generation DES.

In this study, we present the first experience using the MSG technology in humans. Over the last decade, the development of the MSG technology has sought to accelerate stent surface endothelialisation by creating specific parallel microgrooves (figure 1) using highly precise photolithographic techniques. ${ }^{3}$ Over the years, technological improvements have increased the manufacturing accuracy of the groove patterns progressing from micron to submicron resolutions. Improvements in edge, shape and depth definition of the microgrooves resulted in measurable increases in EC responses, demonstrating a peculiar sensitivity of the EC to defined groove features. In vitro studies have shown that MSG surfaces increase EC migration (by 2-3 times), maturity and functionality. ${ }^{5}$ ${ }^{6}$ These biological effects are independent of the material used (metals or polymers) and it is maintained in the presence of antiproliferative drugs. ${ }^{22}$ In addition, porcine studies demonstrated that MSG increased stent endothelialisation (by $17 \%$ at 3 days) and decreased NT (by $30 \%$ at 28 days) compared with identical BMS controls. ${ }^{3}$

In this study, we compared the patterns of stent healing of identical BMS exposing two different luminal surfaces (MSG vs flat) among patients undergoing PCI by performing OCT 3 weeks following stent implantation. To the best of our knowledge, our study represents one of the few studies presenting very early healing data following stent implantation. A striking finding in this study was the fact that in the absence of antiproliferative drugs strut coverage was in a very advanced stage of development by 3 weeks in both stent groups. This important biological finding highlights the significant advances stent technologies have had in the last decade. In the strut coverage analysis, BMS controls displayed a higher percentage of struts fully embedded in neointimal tissue. Although this finding may appear counterintuitive, such differences reflect the ability of the MSG surface to induce a thinner and more organised neointimal formation on the surface of the stent. In our analysis, the MSG group showed lower levels of neointimal formation at the strut and stent-level analysis. Interestingly, at this stage of healing the biological effect of the grooves appears to follow coronary flow favouring the proximal and medial parts of the stent. Furthermore, while in the BMS group layered neointimal tissue was seen in $6 \%$ of the OCT frames analysed, this OCT marker of delayed healing (fibrin deposits) was not seen in any of the OCT frames in the MSG group.

The most consistent biological finding seen in the MSG group was the reduction in neointimal proliferation. When measured as percentage of NIH tissue area relative to the total cross-sectional area of the stented segment, the percentage NIH area was lower through the length of the MSG group compared with BMS. Also, NIH volume measurements in cross-sectional imaging along the longitudinal axis of the MSG stent indicated lower volume of tissue coverage throughout most of the stent length compared with BMS (respectively: 8.9 (5.7-13.6) vs 11.0 (3.9-21.5), $\mathrm{p}=0.86)$. Furthermore, on strut-level analysis we observed similar level $(\sim 22 \%)$ of NT reduction in the MSG stent group (respectively: $0.09(0.04-0.17)$ vs 0.07 $(0.04-0.15), \mathrm{p}=0.83)$ as seen in the previously published porcine studies (20\% reduction). ${ }^{3}$ One of the most important findings is that in the MSG group most of the struts displayed an NT $<120 \mu \mathrm{m}$ throughout the length of the stent (figure 7). This finding is important as it shows the homogeneity of neointimal distribution throughout the surface of the stent.

\section{Study limitations}

This exploratory study using BMS without presence of anitproliferative drug was designed aiming to evaluate the impact of the MSG technology on stent healing. The sample size calculation was based on the estimated $20 \%$ reduction in neointimal proliferation induced by the MSG stent in the porcine studies; however, the study was
BMS

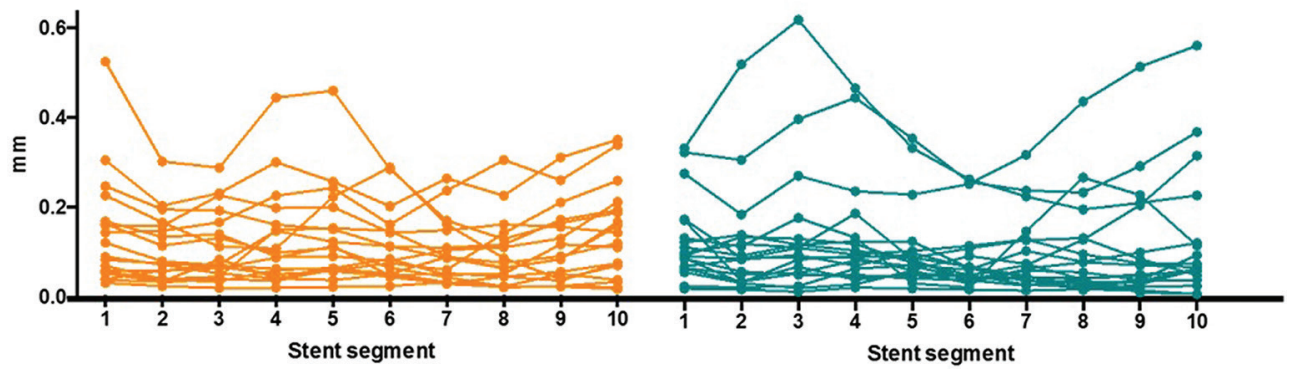

Figure 7 Average neointimal tissue thickness by decile from the most distal segment 1 to the most proximal10 across the stent in each patient. BMS, bare metal stent; MSG, microengineered stent grooves. 
underpowered to demonstrate statistical significances between the studied groups. Additionally, although OCT is a widely accepted tool for the evaluation of stent healing, their limited resolution does not allow the evaluation of true stent endothelialisation. Also, the classification used in this study to score and evaluate strut coverage using OCT aims to describe specific morphological patterns and may have little correlation with biological processes occurring in vivo. Then, the clinical implications of these findings are unknown. Finally, stent failure is a complex and multifactorial phenomenon occurring as the result of multiple inter-related factors evolving over time. This study provides only a snapshot at a single point in time and the final effects on stent healing need to be studied at long term in a larger population.

\section{CONCLUSION}

This clinical study presents the first-in-human implantation of the MSG technology in patients with ischaemic heart disease due to de novo coronary artery lesions. Early 3 weeks OCT analysis suggests that the MSG stents have the potential to induce lower levels of neointimal formation and more mature neointima compared with flat stent surfaces. Large imaging-based-randomised studies ideally in the presence of antiproliferative drugs are needed to confirm this hypothesis. Additionally, we observed higher level of OCT-derived neointimal maturity which indicates faster healing of the stent surface. In the strut coverage analysis, BMS controls displayed a higher percentage of struts fully embedded in neointimal tissue. Although this finding may appear counterintuitive, such differences reflect the ability of the MSG surface to induce a thinner and more organised neointimal formation on the surface of the stent. The biological effects of the MSG stent on EC migration are not affected by the presence of antiproliferative drugs, then this technology has the potential to improve the safety of devices in the presence of drug elution (ie, bioresorbable scaffolds). Further studies of this novel stent technology will assess the clinical outcomes at long-term follow-up.

\footnotetext{
Author affiliations

${ }^{1}$ Universidad Industrial de Santander, Bucaramanga, Colombia

${ }^{2}$ Instituto del Corazon de Bucaramanga, Bucaramanga, Colombia

${ }^{3}$ CRF-Skirball Center for Innovation, Orangeburg, New York, USA

${ }^{4} 3$ rd Department of Cardiology, Medical University of Silesia, Katowice, Poland

${ }^{5}$ Fundacion Cardioinfantil Instituto de Cardiologia, Bogota, Colombia

${ }^{6}$ Instituto Corbic, Envigado, Colombia

${ }^{7}$ Angiografia de Occidente, Cali, Colombia

${ }^{8}$ Abbott Vascular, Santa Clara, California, USA

${ }^{9}$ Cardiology, Cardiovascular Research Foundation/Columbia University Medical Center, New York, USA

${ }^{10}$ Palmaz Scientific, Fremont, California, USA

${ }^{11}$ Skirball Center for Cardiovascular Research, Cardiovascular Research Foundation, Orangeburg, New York, USA

Contributors BV, HH, SH, DE, JAD, AD and CA implemented the trial, monitored data collection and revised the draft paper. PG and AM analysed the data and drafted and revised the draft paper. CS revised the draft paper. JP designed the trial and revised the draft paper. JFG designed the trial, monitored data collection for the whole trial and drafted and revised the paper.
}

Competing interests None declared.

Patient consent Obtained.

Ethics approval The study was approved by the local hospitals and followed the governmental regulations of the government of Colombia, South America.

Provenance and peer review Not commissioned; internally peer reviewed.

Data sharing statement There is no additional data for this paper.

Open Access This is an Open Access article distributed in accordance with the Creative Commons Attribution Non Commercial (CC BY-NC 4.0) license, which permits others to distribute, remix, adapt, build upon this work non-commercially, and license their derivative works on different terms, provided the original work is properly cited and the use is non-commercial. See: http://creativecommons.org/ licenses/by-nc/4.0/

(C) Article author(s) (or their employer(s) unless otherwise stated in the text of the article) 2017. All rights reserved. No commercial use is permitted unless otherwise expressly granted.

\section{REFERENCES}

1. Tada T, Byrne RA, Simunovic I, et al. Risk of stent thrombosis among bare-metal stents, first-generation drug-eluting stents, and secondgeneration drug-eluting stents: results from a registry of 18,334 patients. JACC Cardiovasc Interv 2013;6:1267-74.

2. Joner M, Finn AV, Farb A, et al. Pathology of drug-eluting stents in humans: delayed healing and late thrombotic risk. J Am Coll Cardiol 2006;48:193-202.

3. Sprague EA, Tio F, Ahmed SH, et al. Impact of parallel microengineered stent grooves on endothelial cell migration, proliferation, and function: an in vivo correlation study of the healing response in the coronary swine model. Circ Cardiovasc Interv 2012;5:499-507.

4. Qi P, Chen S, Liu T, et al. New strategies for developing cardiovascular stent surfaces with novel functions (Review). Biointerphases 2014;9:029017.

5. de Mel A, Cousins BG, Seifalian AM. Surface modification of biomaterials: a quest for blood compatibility. Int J Biomater 2012;2012:707863.

6. Palmaz JC, Benson A, Sprague EA. Influence of surface topography on endothelialization of intravascular metallic material. J Vasc Interv Radiol 1999;10:439-44.

7. Bailey SR, Fuss C, Palmaz JC, et al. Surface micro grooves (MG) improve endothelialization rate in vitro and in vivo. J Am Coll Cardiol $2001 ; 37: 70 A$.

8. Sprague EA, Luo J, Palmaz JC. Human aortic endothelial cell migration onto stent surfaces under static and flow conditions. $J$ Vasc Interv Radiol 1997;8:83-92.

9. Palmaz JC, Bailey S, Marton D, et al. Influence of stent design and material composition on procedure outcome. $J$ Vasc Surg 2002;36:1031-9.

10. Cutlip DE, Windecker S, Mehran R, et al. Clinical end points in coronary stent trials: a case for standardized definitions. Circulation 2007;115:2344-51.

11. Varho V, Kiviniemi TO, Nammas W, et al. Early vascular healing after titanium-nitride-oxide-coated stent versus platinumchromium everolimus-eluting stent implantation in patients with acute coronary syndrome. Int $J$ Cardiovasc Imaging 2016;32:1031-9.

12. La Manna A, Prati F, Capodanno D, et al. Head-to-head comparison of early vessel healing by optical coherence tomography after implantation of different stents in the same patient. $J$ Cardiovasc Med 2011;12:328-33.

13. Nishinari M, Shimohama T, Tojo T, et al. Two-week interval optical coherence tomography: imaging evidence on neointimal coverage completion after implantation of the Endeavor zotarolimus-eluting stent. Catheter Cardiovasc Interv 2013;82:E871-E878.

14. Annala AP, Lehtinen T, Kiviniemi TO, et al. Vascular healing early after titanium-nitride-oxide-coated stent implantation assessed by optical coherence tomography. J Invasive Cardiol 2013;25:186-9.

15. Gonzalo N, Serruys PW, Okamura T, et al. Optical coherence tomography patterns of stent restenosis. Am Heart $J$ 2009;158:284-93.

16. Abizaid A, Costa JR. New drug-eluting stents: an overview on biodegradable and polymer-free next-generation stent systems. Circ Cardiovasc Interv 2010;3:384-93.

17. Kang SH, Park KW, Kang DY, et al. Biodegradable-polymer drugeluting stents vs. bare metal stents vs. durable-polymer drug-eluting stents: a systematic review and Bayesian approach network metaanalysis. Eur Heart J 2014;35:1147-58. 
18. Joner M, Finn AV, Farb A, et al. Pathology of drug-eluting stents in humans: delayed healing and late thrombotic risk. J Am Coll Cardiol 2006;48:193-202.

19. Inoue T, Croce K, Morooka T, et al. Vascular inflammation and repair: implications for re-endothelialization, restenosis, and stent thrombosis. JACC Cardiovasc Interv 2011;4:1057-66.

20. Prati $F$, Romagnoli E, Valgimigli $M$, et al. Randomized comparison between 3-month Cre8 DES vs. 1-month Vision/ Multilink8 BMS neointimal coverage assessed by OCT evaluation: the DEMONSTRATE study. Int J Cardiol 2014;176:904-9.

21. Lee JM, Choe W, Kim BK, et al. Comparison of endothelialization and neointimal formation with stents coated with antibodies against CD34 and vascular endothelial-cadherin. Biomaterials 2012;33:8917-27.

22. Bartorelli AL, Trabattoni D, Fabbiocchi F, et al. Synergy of passive coating and targeted drug delivery: the tacrolimus-eluting Janus CarboStent. J Interv Cardiol 2003:16:499-505. 
Correction: Biological effect of microengineered grooved stents on strut healing: a randomised OCT-based comparative study in humans

Vesga B, Hernandez H, Higuera S, et al. Biological effect of microengineered grooved stents on strut healing: a randomised OCT-based comparative study in humans. Open Heart 2017;4:e000521.

The funding and competing interests statement were properly disclosed but erroneously missed from this article when it first published.

Funding: This study was supported by Palmaz Scientific Inc, Fremont, CA.

Competing interests: Charles Simonton is an employee of Abbott Vascular, Santa Clara, California. Julio Palmaz is a founder of Palmaz Scientific, Fremont, California.

Open Access This is an Open Access article distributed in accordance with the Creative Commons Attribution Non Commercial (CC BY-NC 4.0) license, which permits others to distribute, remix, adapt, build upon this work non-commercially, and license their derivative works on different terms, provided the original work is properly cited and the use is non-commercial. See: http:// creativecommons.org/licenses/by-nc/4.0/

Open Heart 2018;5:e000521corr1. doi:10.1136/openhrt-2016-000521corr1

A) Check for updates 